Takashi Akamizu $\cdot$ Hitomi Hiratani

Satoshi Ikegami $\cdot$ Stephen S. Rich

Donald W. Bowden

\title{
Association study of autoimmune thyroid disease at 5q23-q33 in Japanese patients
}

Received: 22 January 2003/ Accepted: 20 February 2003/Published online: 9 April 2003

(C) The Japan Society of Human Genetics and Springer-Verlag 2003

\begin{abstract}
As part of a genome scan to locate familial Graves' disease (GD) and Hashimoto's thyroiditis (HT) genes, an autoimmune thyroid disease (AITD) susceptibility locus has recently been identified at 5q31-q33 in a Japanese population. We performed an association study using six microsatellite markers located at this locus in a set of 440 unrelated Japanese AITD patients and 218 Japanese controls. We found significant allelic association between AITD and three markers located in 5q23-q33. GD demonstrated significant associations with two of these markers, while HT did not show significant associations with any markers. Further, when patients with GD were stratified according to clinical manifestations, the association was significantly different from the other subgroup of each category. These findings suggest the presence of susceptible genes of AITD, especially distinct subgroups of GD, in or near $5 \mathrm{q} 23-\mathrm{q} 33$.
\end{abstract}

Keywords Autoimmune thyroid disease - Graves' disease $\cdot$ Susceptibility gene $\cdot$ Microsatellite marker $\cdot 5 q 23-q 33 \cdot 5 q 31-q 33$

T. Akamizu $(\bowtie) \cdot$ H. Hiratani $\cdot$ S. Ikegami Department of Experimental Therapeutics, Translational Research Center,

Kyoto University Hospital, 54 Shogoin-Kawaharacho,

Sakyo-ku, Kyoto 606-8507, Japan

E-mail: akataka@kuhp.kyoto-u.ac.jp

Tel.: +81-75-7514723

Fax: + 81-75-7514731

D.W. Bowden

Department of Biochemistry,

Wake Forest University School of Medicine,

Winston-Salem, North Carolina, 27157, USA

S.S. Rich

Department of Public Health Science,

Wake Forest University School of Medicine,

Winston-Salem, North Carolina, 27157, USA

\section{Introduction}

The genetic basis of autoimmune thyroid disease (AITD), which includes Graves' disease (GD) and Hashimoto's thyroiditis (HT), is thought to be polygenic (Gough 2000; Brix and Hegedus 1998). Several genetic factors associated with AITD have been tentatively identified by candidate-gene and genome-scanning approaches. They include HLA, cytotoxic T-lymphocyteassociated-4 (CTLA-4), and TSHR gene, and other chromosomal regions, such as 14q31 (GD-1), 20q11.2 (GD-2), Xq21.33-22 (GD-3), 13q32 (HT-1), 12q22, 18q21 (IDDM 6), and Xp11 (Farid et al. 1979; Uno et al. 1981; Yanagawa et al. 1995; Donner et al. 1997; Vaidya et al. 1999; Barbesino et al. 1998; Tomer et al. 1999; Vaidya et al. 2000; Sale et al. 1997; Akamizu et al. 2000). Evidence for AITD genes, however, varies among researchers or populations, and no consensus has been obtained.

Recently, Sakai and co-workers mapped susceptibility loci for HT to 8q23-q24 and AITD to 5q31-q33 by multipoint affected sib-pair linkage analysis in a collection of Japanese AITD families (Sakai et al. 2001). First, chromosome 8q23-q24, which encompasses the thyroglobulin gene, yielded suggestive evidence for linkage to HT with an MLS of 3.77 at D8S272. A recent report confirmed that the thyroglobulin gene is linked and associated with AITD (Tomer et al. 2002). Secondly, chromosome 5q31-q33 yielded suggestive evidence for linkage to AITD with an MLS of 3.14 at D5S436. Chromosome 5q31-q33 includes a cytokine gene cluster and other immune-related genes, and has been reported to be associated or linked to allergic diseases such as asthma and atopic dermatitis (Meyers et al. 1994; Postma et al. 1995; Lonjou et al. 2000). Considering that AITD is an autoimmune disease, this is an intriguing region, where susceptible genes may exist.

In this study we attempted to confirm evidence for the presence of susceptibility genes in or near 5q23-q33 by association analysis, using several microsatellite markers, 
including D5S436, the linked marker from the genome screen. In addition, we carried out subgroup analysis of Graves' patients based on clinical manifestations in different subgroups and analyzed if the patterns of their associations with these markers were different between subgroups.

\section{Subjects and Methods}

Study subjects

Four hundred and forty unrelated Japanese individuals with AITD (337 female, 103 male) were evaluated. In cases where more than one individual from a family was collected, data from only a single individual from the family was included in the genetic analysis. Patients were classed as having either GD $(n=241)$, HT $(n=139)$, primary hypothyroidism with TSH-binding inhibitory immunoglobulin (TBII) $(n=35)$, or hypothyroidism without TBII $(n=25)$. These patients were diagnosed and assayed for antibodies as described previously (Sale et al. 1997; Akamizu et al. 2000). As an unaffected control population, we have also collected an expanded set of controls, consisting of 218 unrelated Japanese individuals (89 male, 129 female). Informed consent was obtained from all the subjects used in this study and the present study was approved by the ethical committee of Kyoto University Graduate School of Medicine.

Genotyping loci at 5q23-q33

Loci at 5q15-q33 were genotyped using seven microsatellite markers derived from the ABI PRISM Linkage Mapping Set Version 2 (Table 1). PCR was performed using the GeneAmp System 9600 with standard protocols. The PCR products were analyzed by electrophoresis through a $6 \%$ denaturing polyacrylamide gel using an ABI 373 automated sequencer apparatus, and the resulting data were analyzed with Genescan software (V 1.2) (Akamizu et al. 2000).

\section{Association analyses}

The frequencies of alleles of loci at 5q23-q33 in the Japanese were calculated from the control populations. Male and female frequencies were compared using the RXC program (George Carmody, Carleton University, Ottawa, Canada), which carries out Monte Carlo simulations (Roff 1989; Waye et al. 1994) to calculate the statistical significance of contingency tables. Because the numbers of male patients were too small, compared with those of females, and patients and controls were not matched for gender, we have presented the data and results for all patients (males + females) throughout the tables. Results from female and male data are noted in the text where their mention seemed relevant. In all cases the allele frequencies in the control male and female allele frequencies were not significantly different, and they were consequently pooled. Rare alleles, e.g., alleles with frequencies less than 0.014 in the population, were pooled for analysis as noted in Table 2. Association analyses between controls and patients were carried out using a contingency $2 \times 2$ table to calculate an odds ratio and $\chi^{2}$. For multiple-comparisons procedures, $P$ values from $\chi^{2}$ analysis were corrected by the method of Bonferroni adjustment (Akamizu et al. 2000; Rosner 1990). $P$ values less than $0.05 / N$ (where $N$ is the number of alleles of each marker shown in Table 2) were considered significant. Pooled alleles were considered as one. For example, $N$ was 8 in D5S2115.

Tests for risk associated with specific alleles and interaction between AITD associated alleles

Alleles of markers that showed evidence of significant association with AITD were evaluated for the relative risk which they contributed to disease susceptibility. These evaluations were also carried out using a conventional $2 \times 2$ table to calculate an odds ratio and $\chi^{2}$.

\section{Clinical manifestations of Graves' patients}

Patients with GD were divided into subgroups based upon various clinical manifestations: goiter size, ophthalmopathy, and titer of anti-TSH receptor antibody. Goiter size and titer of anti-TSH receptor antibody were measured at onset or before treatment. The size of goiter was determined by measuring the transverse diameter. The patients were divided into two subgroups, large $(\geq 5 \mathrm{~cm})$ $(n=119)$ or small $(<5 \mathrm{~cm})(n=78)$ goiter groups. Patients with TAO were defined by the presence of proptosis [American Thyroid Association (ATA) class 3] or higher ATA class (diplopia, corneal, and optic-nerve involvement) (Werner 1977). GD patients without and with ophthalmopathy were 111 and 88, respectively. For antiTSH receptor antibodies, TBII (TSH binding inhibitor immunoglobulin) activity (Rees Smith et al. 1988; Endo et al. 1978) was measured, because TBII activity was most frequently measured at the onset of GD as an anti-TSH receptor antibody. GD patients with potent $(\geq 50 \%)$ and weak $(<50 \%)$ TBII were 64 and 90 , respectively. Patients who responded well to anti-thyroid drugs and went into remission were classed as "excellent responders" $(n=32)$, while those who needed anti-thyroid drugs (propylthiouracil or methimazol) after two years' treatment to maintain euthyroid function were classed as "poor responders" $(n=119)$.

\section{Results}

\section{Association studies}

Table 1 shows chromosome localization, allele size range and heterozygosity of $5 \mathrm{q}$ microsatellite markers in a Japanese population. Six markers are located in 5q23q33. D5S2011, D5S2090 and D5S2049 were not used in the previous study of Sakai et al. (2001). Table 2 shows
Table 1 Chromosome localization, allele size range, and heterozygosity of $5 \mathrm{q}$ microsatellite markers in a Japanese population

${ }^{a}$ Heterozygosity in Japanese controls of this study

\begin{tabular}{llllr}
\hline Microsatellite marker & \multicolumn{2}{l}{ Map position } & \multirow{2}{*}{ Allele size range (bp) } & HET $^{\mathrm{a}}$ \\
\cline { 2 - 3 } & \multicolumn{2}{l}{ Genethon genetic (cM) } & Ideogram & \\
\hline D5S2115 & 138.6 & $5 \mathrm{q} 23-\mathrm{q} 31$ & $152-182$ & 0.787 \\
D5S2011 & 143.7 & $5 \mathrm{q} 31$ & $142-160$ & 0.804 \\
D5S436 & 147.2 & $5 \mathrm{q} 31-\mathrm{q} 33$ & $240-258$ & 0.732 \\
D5S2090 & 149.9 & $5 \mathrm{q} 31-\mathrm{q} 33$ & $193-209$ & 0.684 \\
D5S410 & 156.0 & $5 \mathrm{q} 33$ & $330-342$ & 0.648 \\
D5S2049 & 160.4 & $5 \mathrm{q} 33$ & $87-103$ & 0.560 \\
\hline
\end{tabular}


Table 2 Polymorphism allele frequencies in Japanese AITD patients and controls. Frequencies in bold are significantly different in patients vs controls at $P<0.05$ in the method of Bonferroni adjustment; italics show that the initial frequencies are $P<0.05$ but become non-significant after the adjustment; $n=$ total number alleles

\begin{tabular}{|c|c|c|c|c|c|c|c|}
\hline \multirow[t]{2}{*}{ Allele } & \multirow[t]{2}{*}{ Base pairs } & \multirow[t]{2}{*}{ Controls } & \multirow[t]{2}{*}{ AITD } & \multirow[t]{2}{*}{ GD } & \multirow[t]{2}{*}{ HT } & \multicolumn{2}{|c|}{ Hypothyroidism $^{a, b}$} \\
\hline & & & & & & $\mathrm{TBII}(+)$ & TBII(-) \\
\hline D5S2115 & & $n=326$ & $n=800$ & $n=419$ & $n=266$ & $n=70$ & $n=40$ \\
\hline 1 & 164 & 0.043 & 0.035 & 0.024 & 0.041 & 0.057 & 0.068 \\
\hline 2 & 168 & 0.049 & 0.031 & 0.038 & 0.030 & 0.000 & 0.023 \\
\hline 3 & 170 & 0.138 & 0.120 & 0.131 & 0.117 & 0.071 & 0.114 \\
\hline 4 & 172 & 0.390 & 0.490 & 0.499 & 0.485 & 0.514 & 0.409 \\
\hline 5 & 174 & 0.150 & 0.141 & 0.124 & 0.173 & 0.143 & 0.114 \\
\hline 6 & 176 & 0.107 & 0.110 & 0.126 & 0.075 & 0.143 & 0.114 \\
\hline 7 & 178 & 0.058 & 0.020 & 0.014 & 0.019 & 0.043 & 0.045 \\
\hline Pooled alleles ${ }^{\mathrm{a}}$ & & 0.064 & 0.053 & 0.043 & 0.060 & 0.029 & 0.114 \\
\hline D5S2011 & & $n=368$ & $n=880$ & $n=480$ & $n=282$ & $n=68$ & $n=50$ \\
\hline 1 & 144 & 0.019 & 0.003 & 0.004 & 0.004 & 0.000 & 0.000 \\
\hline 2 & 146 & 0.215 & 0.230 & 0.240 & 0.220 & 0.206 & 0.220 \\
\hline 3 & 148 & 0.313 & 0.377 & 0.400 & 0.340 & 0.353 & 0.400 \\
\hline 4 & 150 & 0.190 & 0.175 & 0.150 & 0.220 & 0.221 & 0.100 \\
\hline 5 & 152 & 0.071 & 0.044 & 0.044 & 0.043 & 0.044 & 0.060 \\
\hline 6 & 154 & 0.068 & 0.058 & 0.060 & 0.071 & 0.000 & 0.040 \\
\hline 7 & 156 & 0.057 & 0.044 & 0.031 & 0.046 & 0.132 & 0.040 \\
\hline 8 & 158 & 0.052 & 0.065 & 0.069 & 0.053 & 0.044 & 0.120 \\
\hline Pooled alleles ${ }^{\mathrm{b}}$ & & 0.016 & 0.003 & 0.002 & 0.004 & 0.000 & 0.020 \\
\hline D5S436 & & $n=342$ & $n=799$ & $n=413$ & $n=266$ & $n=70$ & $n=50$ \\
\hline 1 & 240 & 0.070 & 0.091 & 0.087 & 0.083 & 0.157 & 0.080 \\
\hline 2 & 242 & 0.447 & 0.468 & 0.460 & 0.508 & 0.371 & 0.460 \\
\hline 3 & 244 & 0.026 & 0.033 & 0.034 & 0.038 & 0.029 & 0.000 \\
\hline 4 & 246 & 0.135 & 0.135 & 0.136 & 0.135 & 0.114 & 0.160 \\
\hline 5 & 248 & 0.120 & 0.078 & 0.077 & 0.068 & 0.114 & 0.080 \\
\hline 6 & 250 & 0.173 & 0.139 & 0.143 & 0.128 & 0.157 & 0.140 \\
\hline 7 & 252 & 0.018 & 0.025 & 0.024 & 0.023 & 0.000 & 0.080 \\
\hline Pooled alleles ${ }^{\mathrm{c}}$ & & 0.012 & 0.031 & 0.039 & 0.019 & 0.057 & 0.000 \\
\hline D5S2090 & & $n=376$ & $n=880$ & $n=482$ & $n=278$ & $n=70$ & $n=50$ \\
\hline 1 & 193 & 0.037 & 0.063 & 0.068 & 0.054 & 0.100 & 0.000 \\
\hline 2 & 195 & 0.508 & 0.485 & 0.473 & 0.471 & 0.543 & 0.600 \\
\hline 3 & 197 & 0.101 & 0.085 & 0.093 & 0.076 & 0.071 & 0.080 \\
\hline 4 & 201 & 0.191 & 0.173 & 0.178 & 0.180 & 0.157 & 0.100 \\
\hline 5 & 203 & 0.021 & 0.031 & 0.031 & 0.014 & 0.071 & 0.060 \\
\hline 6 & 205 & 0.088 & 0.113 & 0.108 & 0.151 & 0.043 & 0.040 \\
\hline 7 & 207 & 0.040 & 0.039 & 0.035 & 0.047 & 0.014 & 0.060 \\
\hline Pooled alleles ${ }^{\mathrm{d}}$ & & 0.013 & 0.013 & 0.012 & 0.007 & 0.000 & 0.060 \\
\hline D5S410 & & $n=367$ & $n=816$ & $n=430$ & $n=280$ & $n=62$ & $n=44$ \\
\hline 1 & 330 & 0.030 & 0.005 & 0.002 & 0.007 & 0.000 & 0.023 \\
\hline 2 & 332 & 0.302 & 0.237 & 0.212 & 0.214 & 0.403 & 0.386 \\
\hline 3 & 334 & 0.493 & 0.533 & 0.551 & 0.557 & 0.435 & 0.341 \\
\hline 4 & 336 & 0.057 & 0.086 & 0.098 & 0.046 & 0.129 & 0.159 \\
\hline 5 & 338 & 0.114 & 0.137 & 0.137 & 0.168 & 0.032 & 0.091 \\
\hline Pooled alleles & & 0.003 & 0.002 & 0.000 & 0.007 & 0.000 & 0.000 \\
\hline D5S2049 & & $n=338$ & $n=868$ & $n=476$ & $n=284$ & $n=62$ & $n=48$ \\
\hline 1 & 91 & 0.018 & 0.025 & 0.025 & 0.032 & 0.000 & 0.022 \\
\hline 2 & 93 & 0.163 & 0.175 & 0.168 & 0.169 & 0.194 & 0.261 \\
\hline 3 & 95 & 0.630 & 0.577 & 0.574 & 0.570 & 0.661 & 0.543 \\
\hline 4 & 97 & 0.098 & 0.100 & 0.111 & 0.102 & 0.016 & 0.087 \\
\hline 5 & 101 & 0.077 & 0.104 & 0.105 & 0.106 & 0.113 & 0.065 \\
\hline Pooled alleles ${ }^{f}$ & & 0.015 & 0.018 & 0.017 & 0.021 & 0.016 & 0.022 \\
\hline
\end{tabular}

${ }^{\mathrm{a}}$ Pooled alleles: 152, 154, 156, 158, 160, 162, 166, 180, $182 \mathrm{bp}($ control frequencies $<0.015)$

${ }^{\mathrm{b}}$ Pooled alleles of $142,160 \mathrm{bp}$ (control frequencies $<0.012$ )

${ }^{c}$ Pooled alleles:254, 256, 258 bp (control frequencies $<0.013$ )

${ }^{\mathrm{d}}$ Pooled alleles:199, $209 \mathrm{bp}$ (control frequencies <0.012)

${ }^{\text {e}}$ Pooled alleles:340, 342 bp (control frequencies $<0.012$ )

${ }^{f}$ Pooled alleles:87, 89, 99, 103 bp (control frequencies $\left.<0.012\right)$

the results of the association analysis of polymorphic alleles of these seven markers and AITD. Significant differences between the allele frequencies of cases and controls are reported on the basis of allele-specific tests of significance, using a $\chi^{2}$ statistic with one degree of freedom. Table 3 summarizes $P$ values of the $\chi^{2}$ statistic. Frequencies of alleles of all these markers in the control Japanese males and females were not significantly 
Table $3 P$ values of chi square analysis in association study of Japanese AITD patients. $P$ values in bold are significantly different in patients vs controls at $P<0.05$ in the method of Bonferroni adjustment

\begin{tabular}{|c|c|c|c|c|c|c|c|}
\hline \multirow[t]{2}{*}{ Allele } & \multirow[t]{2}{*}{ Base pairs } & \multirow[t]{2}{*}{ AITD } & \multirow[t]{2}{*}{ GD } & \multirow[t]{2}{*}{ HT } & \multicolumn{2}{|c|}{ Hypothyroidism } & \multirow[t]{2}{*}{ Effect } \\
\hline & & & & & $\mathrm{TBII}(+)$ & TBII(-) & \\
\hline \multicolumn{8}{|l|}{ D5S2115 } \\
\hline Allele 4 & 172 & 0.00217 & 0.00295 & 0.0198 & 0.0544 & 0.803 & + \\
\hline Allele 7 & 178 & $7.87 \times 10^{-4}$ & $9.48 \times 10^{-4}$ & 0.0154 & 0.609 & 0.730 & - \\
\hline \multicolumn{8}{|l|}{ D5S2011 } \\
\hline Allele 1 & 144 & 0.00479 & 0.0364 & 0.0761 & 0.252 & 0.325 & - \\
\hline \multicolumn{8}{|l|}{ D5S410 } \\
\hline Allele 1 & 330 & $3.64 \times 10^{-4}$ & 0.00140 & 0.0403 & 0.167 & 0.787 & - \\
\hline Allele 2 & 332 & 0.0164 & 0.00330 & 0.0117 & 0.1150 & 0.256 & - \\
\hline
\end{tabular}

different $(P=0.12-0.98)$ and the data were pooled for analysis. We found significant allelic association between AITD and three of six markers. Of three markers, two showed significant allelic association with GD, but D5S2011 did not. For the D5S410 polymorphism, allele 2 (332 bp) was significantly decreased only in GD cases. HT and other hypothyroidisms did not show significant associations with any markers. Although several alleles of these markers showed $P$ values less than 0.05 in association analyses (italic figures in Table 2), they were considered non-significant after correction by the method of Bonferroni adjustment for multiplecomparisons procedures.

Risks associated with AITD susceptibility alleles

The increased risk for developing AITD in individuals with specific susceptibility alleles of six microsatellite markers was evaluated by calculating the odds ratios (i.e., risk ratios), as shown in Table 4. Allele 4 of D5S2115 showed increased risks of 1.5. Similarly, the reduced risk for developing AITD was evaluated by calculating the odds ratios. The reduced risks were $0.2-0.3$.

\section{Clinical manifestations of Graves' disease}

To further examine association of GD with $5 \mathrm{q}$ markers, patients with GD were categorized into subgroups, based on clinical findings (Table 5). GD without ophthalmopathy and GD of "poor drug responders" were associated with most or all alleles that showed significant association with GD all. Patients with large goiter $(\geq 5 \mathrm{~cm})$ also showed similar tendency, although they associated with fewer alleles (two alleles). For the TBII activity, GD with weak TBII was associated with allele 4 of D5S410 that also showed significant association with GD of "excellent drug responders".

\section{Discussion}

We found significant association between AITD/GD and several microsatellite markers located in 5q23-33. None of these markers were not associated with HT or other hypothyroidism. Although it might be possible that analysis of HT or other hypothyroidism has less power than that of AITD or GD because HT or other hypothyroidism groups are fewer in number, this finding supports the previously published linkage analysis evidence that chromosome $5 \mathrm{q} 31-33$ contains AITD/GD susceptibility gene(s), but not HT (Sakai et al. 2001). Although alleles of D5S436 showed a strong linkage with AITD and GD in the previous genome-wide screen, allelic association with them became non-significant after the correction by the method of Bonferroni adjustment. These observations suggest that D5S2115 and/or D5S410 may be more likely locations of AITD and GD susceptibility genes than D5S436 in our population. Considering that genetic distance between D5S2115 and D5S410 is approximately $20 \mathrm{cM}$, it is unlikely that the two markers are both in linkage disequilibrium with a single variation of the putative susceptibility gene of AITD and GD. Instead, they might suggest that multiple independent susceptibility genes exist within 5q23-33.

Chromosome 5q23-33 contains the human cytokine gene cluster $(5 \mathrm{q} 31.1)$, containing genes for interleukin (IL)-3, IL-4, IL-5, IL-9, IL-13, granulocyte/macrophage
Table 4 Risks associated with AITD susceptibility alleles

\begin{tabular}{llcllll}
\hline Locus & & Cases & Controls & $\begin{array}{l}\text { Odds } \\
\text { ratio }\end{array}$ & $\begin{array}{l}\text { 95\% confidence } \\
\text { interval }\end{array}$ & $P$ value \\
\hline D5S2115 & Allele 4' 172 bp & 392 & 127 & 1.5 & $1.2-2.0$ & 0.00217 \\
& NOT 'allele 4' 172 bp & 408 & 199 & & & \\
& Allele 7' 178 bp & 16 & 19 & 0.3 & $0.2-0.6$ & $7.87 \times 10^{-4}$ \\
& NOT 'allele 7' 178 bp & 784 & 307 & & & \\
D5S2011 & Allele 1' 144 bp & 3 & 7 & 0.2 & $0.0-0.7$ & 0.00479 \\
& NOT ‘allele 1'144 bp & 877 & 361 & & & \\
D5S410 & Allele 1' 330 bp & 4 & 11 & 0.2 & $0.1-0.5$ & $3.64 \times 10^{-4}$ \\
& NOT 'allele 1'330 bp & 812 & 356 & & & \\
\hline
\end{tabular}




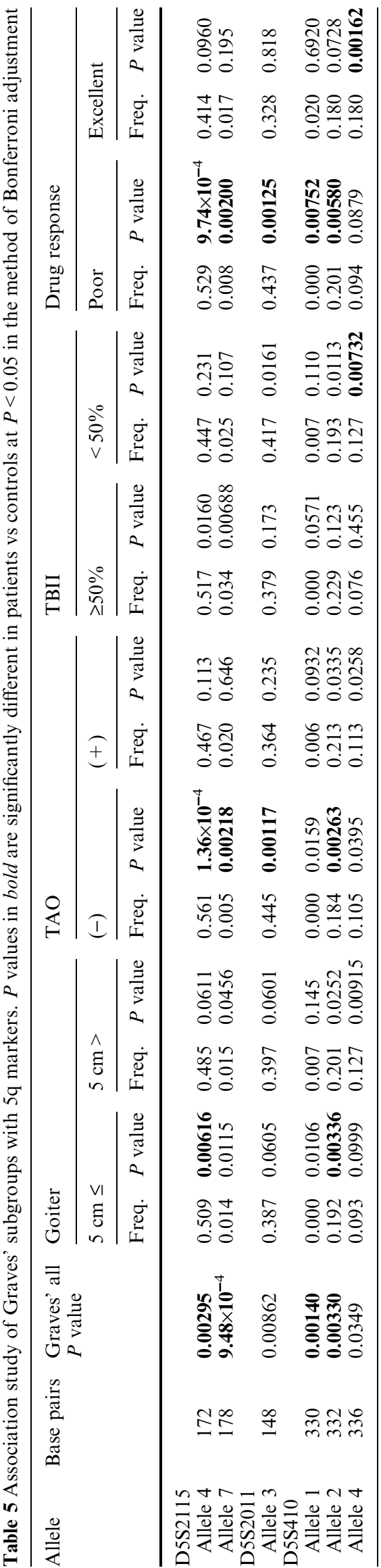

colony-stimulating factor (GM-CSF) and interferon regulatory factor 1 (IRF-1) (van Leeuwen et al. 1989; Rioux et al. 1998; Wills-Karp 2000; Le Beau et al. 1993). Other immune-related molecules, such as $\beta_{2}$ adrenergic receptor (5q31-q32) and CSF receptor 1 (CSF1R) (5q33q35), are also localized to this region (Mirow et al. 1994; Mansur et al. 1998). IL-4, IL-13, IL-5 and IL-9, which are the T-helper type 2 (Th2) cytokine gene cluster, have been linked to asthma or related phenotypes in many studies (Meyers et al. 1994; Postma et al. 1995; Lonjou et al. 2000; Wills-Karp 2000). The fact that GD tended to show a stronger association with $5 \mathrm{q}$ markers than HT both in the previous (D5S436) and the present study (D5S2115) may reflect that GD is thought to be a Th2 disease, while HT is likely a Th1 disease (Heuer et al. 1996; Yamada et al. 2000). Indeed, the association of GD with IL-4 has been reported (Hunt et al. 2000).

When patients with GD were stratified based on clinical manifestations, patterns of allelic association with these markers were different between subgroups. This finding suggests that GD is heterogeneous and that different susceptibility genes might contribute to GD phenotypes. "GD without ophthalomopathy" and "GD of poor drug response" were both associated with the same several alleles, although the clinical significance of this association pattern is not clear. "GD with large goiter" also tended to show a similar association pattern to these subgroups. This finding may reflect the fact that GD patients with large goiter are harder to become in remission by ATD treatment than those with small goiter (Young et al. 1988; Laurberg et al. 1986). The finding that "GD with weak anti-TSH receptor antibody" and "GD of excellent drug response" associated with the same allele (allele 4 of D5S410) also corresponds to the clinical observation that patients with weak anti-TSH receptor antibody tended to easily become in remission (Young et al. 1988; Michelangeli et al. 1998). Thus, these association patterns between subgroups may help to clarify the genetic basis that contributes to forming the phenotypes of GD.

In the present study, we presented the data and results for all patients (males + females), since the numbers of male patients were too small compared with that of females, patients and controls were not matched for gender, and frequencies of alleles of markers in the control males and females were not significantly different. In fact, when we analyzed the data using female subjects alone, we found the same association for most of strongly associated alleles, though weaker in some alleles (data not shown).

Through association analysis using several polymorphic markers, we have confirmed the presence of susceptibility genes in or near the 5q31-q33 region previously identified by linkage analysis to contain a susceptibility locus for AITD by the genome-wide screening in Japanese. Since this region contains a cytokine gene cluster, it will be quite interesting to perform further analysis: (1) to narrow the susceptibility region by using $50-100 \mathrm{~kb}$-spaced polymorphic 
markers spanning this region; (2) to find single-nucleotide polymorphism of candidate genes located in this region, which are not only associated or linked, but also functionally related to AITD.

Acknowledgements This work was supported by grants-in-aid from the Ministry of Education, Science, Culture, Sports and Technology of Japan (nos. 12204065 and 13204046) and the Ministry of Health, Labor and Welfare, Japan to T.A.. We are indebted to many doctors, especially Drs. Keiichi Kamijo and Kishiko Nakamura, for collecting blood samples of AITD patients and normal subjects, respectively, and also to the patients and unaffected individuals who participated in this study. We thank Miss Maki Kouchi for excellent secretarial assistance.

\section{References}

Akamizu T, Sale M, Rich SS, Hiratani H, Noh JY, Kanamoto N, Saijo M, Miyamoto Y, Saito Y, Nakao K, Bowden DW (2000) Association of autoimmune thyroid disease with microsatellite markers for the thyrotropin receptor gene and CTLA-4 in Japanese patients. Thyroid 10:851-858

Barbesino G, Tomer Y, Concepcion ES, Davies TF, Greenberg DA (1998) Linkage analysis of candidate genes in autoimmune thyroid disease. II. Selected gender-related genes and the $\mathrm{X}$-chromosome. International Consortium for the Genetics of Autoimmune Thyroid Disease. J Clin Endocrinol Metab 83:3290-3295

Brix TH, Kyvik KO, Hegedus L (1998) What is the evidence of genetic factors in the etiology of Graves' disease? A brief review. Thyroid 8:727-734

Donner H, Rau H, Walfish PG, Braun, J, Siegmund T, Finke R, Herwig J, Usadel KH, Badenhoop K (1997) CTLA4 Alanine-17 confers genetic susceptibility to Graves' disease and to type 1 diabetes mellitus. J Clin Endocrinol Metab 82:143-146

Endo K, Kasagi K, Konishi J, Ikekubo K, Okuno T, Takeda Y, Mori T, Torizuka K (1978) Detection and properties of TSHbinding inhibitor immunoglobulins in patients with Graves' disease and Hashimoto's thyroiditis. J Clin Endocrinol Metab 46:734-739

Farid NR, Sampson L, Noel EP, Barnard JM, Mandeville R, Larsen B, Marshall WH, Carter ND (1979) A study of human leukocyte D locus related antigens in Graves' disease. J Clin Invest 63:108-113

Gough SC (2000) The genetics of Graves' disease. Endocrinol Metab Clin North Am 29:255-266

Heuer M, Aust G, Ode-Hakim S, Scherbaum WA (1996) Different cytokine mRNA profiles in Graves' disease, Hashimoto's thyroiditis, and nonautoimmune thyroid disorders determined by quantitative reverse transcriptase polymerase chain reaction (RT-PCR). Thyroid 6:97-106

Hunt PJ, Marshall SE, Weetman AP, Bell JI, Wass JA, Welsh KI (2000) Cytokine gene polymorphisms in autoimmune thyroid disease. J Clin Endocrinol Metab 85:1984-1988

Laurberg P, Buchholtz Hansen PE, Iversen E, Eskjaer Jensen S, Weeke J (1986) Goitre size and outcome of medical treatment of Graves' disease. Acta Endocrinol (Copenh) 111:39-43

Le Beau MM, Espinosa R 3rd, Neuman WL, Stock W, Roulston D, Larson RA, Keinanen M, Westbrook CA (1993) Cytogenetic and molecular delineation of the smallest commonly deleted region of chromosome 5 in malignant myeloid diseases. Proc Natl Acad Sci USA 90:5484-5488

Lonjou C, Barnes K, Chen H, Cookson WO, Deichmann KA, Hall IP, Holloway JW, Laitinen T, Palmer LJ, Wjst M, Morton NE (2000) A first trial of retrospective collaboration for positional cloning in complex inheritance: assay of the cytokine region on chromosome 5 by the consortium on asthma genetics (COAG). Proc Natl Acad Sci USA 97:10942-10947
Mansur AH, Bishop DT, Markham AF, Britton J, Morrison JF (1998) Association study of asthma and atopy traits and chromosome 5q cytokine cluster markers. Clin Exp Allergy 28:141150

Meyers DA, Postma DS, Panhuysen CI, Xu J, Amelung PJ, Levitt RC, Bleecker ER (1994) Evidence for a locus regulating total serum IgE levels mapping to chromosome 5. Genomics 23:464 470

Michelangeli V, Poon C, Taft J, Newnham H, Topliss D, Colman P (1998) The prognostic value of thyrotropin receptor antibody measurement in the early stages of treatment of Graves' disease with antithyroid drugs. Thyroid 8:119-124

Mirow AL, Kristbjanarson H, Egeland JA, Shilling P, Helgason T, Gillin JC, Hirsch S, Kelsoe JR (1994) A linkage study of distal chromosome 5q and bipolar disorder. Biol Psychiatry 36:223229

Postma DS, Bleecker ER, Amelung PJ, Holroyd KJ, Xu J, Panhuysen CI, Meyers DA, Levitt RC (1995) Genetic susceptibility to asthma-bronchial hyperresponsiveness coinherited with a major gene for atopy. N Engl J Med 333:894-900

Rees Smith B, McLachlan SM, Furmaniak J (1988) Autoantibodies to the thyrotropin receptor. Endocr Rev 9:106-121

Rioux JD, Stone VA, Daly MJ, Cargill M, Green T, Nguyen H, Nutman T, Zimmerman PA, Tucker MA, Hudson T, Goldstein AM, Lander E, Lin AY (1998) Familial eosinophilia maps to the cytokine gene cluster on human chromosomal region 5q31q33. Am J Hum Genet 63:1086-1094

Roff DA, Bentzen P (1989) The statistical analysis of mitochondrial DNA polymorphisms: $\mathrm{c} 2$ and the problem of small samples. Mol Biol Evol 6:539-545

Rosner B (1990) Fundamentals of Biostatistics. PWS-Kent, Boston, pp 303-305

Sakai K, Shirasawa S, Ishikawa N, Ito K, Tamai H, Kuma K, Akamizu T, Tanimura M, Furugaki K, Yamamoto K, Sasazuki T (2001) Identification of susceptibility loci for autoimmune thyroid disease to 5q31-q33 and Hashimoto's thyroiditis to 8q23-q24 by multipoint affected sib-pair linkage analysis in Japanese. Hum Mol Genet 10:1379-1386

Sale MM, Akamizu T, Howard TD, Yokota T, Nakao K, Mori T, Iwasaki H, Rich SS, Jennings-Gee JE, Yamada M, Bowden DW. (1997) Association of autoimmune thyroid disease with a microsatellite marker for the thyrotropin receptor gene and CTLA-4 in a Japanese population. Proc Assoc Amer Physician 109:453-461

Tomer Y, Barbesino G, Greenberg DA, Concepcion E, Davies TF (1999) Mapping the major susceptibility loci for familial Graves' and Hashimoto's diseases: evidence for genetic heterogeneity and gene interactions. J Clin Endocrinol Metab $84: 4656-4664$

Tomer Y, Greenberg DA, Concepcion E, Ban Y, Davies TF (2002) Thyroglobulin is a thyroid specific gene for the familial autoimmune thyroid diseases. J Clin Endocrinol Metab 87:404-407

Uno H, Sasazuki T, Tamai H, Matsumoto H (1981) Two major genes, linked to HLA and Gm, control susceptibility to Graves' disease. Nature 292:768-770

Vaidya B, Imrie H, Perros P, Young ET, Kelly WF, Carr D, Large DM, Toft AD, McCarthy MI, Kendall-Taylor P, Pearce SH (1999) The cytotoxic T lymphocyte antigen-4 is a major Graves' disease locus. Hum Mol Genet 8:1195-1199

Vaidya B, Imrie H, Perros P, Young ET, Kelly WF, Carr D, Large DM, Toft AD, Kendall-Taylor P, Pearce SH (2000) Evidence for a new Graves disease susceptibility locus at chromosome 18q21. Am J Hum Genet 66:1710-1714

van Leeuwen BH, Martinson ME, Webb GC, Young IG (1989) Molecular organization of the cytokine gene cluster, involving the human IL-3, IL-4, IL-5, and GM-CSF genes, on human chromosome 5. Blood 73:1142-1148

Waye JS, Eng B, Ni HY, Blajchman MA, Carmody G (1994) Trinucleotide repeat polymorphism within the human antithrombin gene (AT3): allele frequency data for three population groups. Mol Cell Probes 8:149-154 
Werner SC (1977) Modification of the classification of the eye changes of Graves' disease: recommendations of the Ad Hoc Committee of the American Thyroid Association. J Clin Endocrinol Metab 44:203-204

Wills-Karp M. (2000) The gene encoding interleukin-13: a susceptibility locus for asthma and related traits. Respir Res $1: 19-23$

Yamada T, Sato A, Komiya I, Nishimori T, Ito Y, Terao A, Eto S, Tanaka Y (2000) An elevation of serum immunoglobulin E provides a new aspect of hyperthyroid Graves' disease. J Clin Endocrinol Metab 85:2775-2778
Yanagawa T, Hidaka Y, Guimaraes V, Soliman M, DeGroot LJ (1995) CTLA-4 gene polymorphism associated with Graves' disease in a Caucasian population. J Clin Endocrinol Metab 80:41-45

Young ET, Steel NR, Taylor JJ, Stephenson AM, Stratton A, Holcombe M, Kendall-Taylor P (1988) Prediction of remission after antithyroid drug treatment in Graves' disease. Q J Med 66:175-189 